\title{
Estudo clínico da infecção de felinos pelo vírus da leucemia felina em São Paulo
}

\section{Clinical studies of feline leukemia virus infection among cats in São Paulo}

\author{
Mitika K. Hagiwara1 , Archivaldo Reche Júnior² , Silvia Regina Ricci Lucas
}

\section{Resumo}

Para avaliar a freqüência da infecção pelo vírus da leucemia felina (VLF), 298 gatos doentes, atendidos no Hospital Veterinário da Faculdade de Medicina Veterinária e Zootecnia da Universidade de São Paulo, foram submetidos ao teste imunoenzimático para a detecção de antígenos virais do VLF (Leukassay F., Pitman Moore Inc.). Dos animais submetidos ao teste, $37(12,5 \%)$ apresentaram-se positivos, com diagnóstico clínico de hemobartonelose (10), linfoma mediastinal (7), icterícia e febre (3), peritonite infecciosa felina (2), anemia hipoplásica (2), uveíte (2), gastroenterite (2), trombocitopenia (2), periodontite (2) atrofia do timo (1), doença respiratória crônica (1) e contactante e assintomático (1). A maioria dos animais acometidos situava-se na faixa etária de 30 a 36 meses, tendo o mais jovem um mês e o mais velho 12 anos de idade. A infecção foi observada com maior freqüência entre os machos, que responderam por $67,5 \%$ dos casos, havendo também predominância dos felinos sem raça definida.

Palavras chave: felinos; leucemia felina; vírus

\section{Introdução}

O complexo leucemia felina que engloba os processos proliferativos ou degenerativos das linhagens celulares sangüíneas, como também diversas formas de imunossupressão e de infecções crônicas, tem como agente etiológico causal um retrovírus oncogênico denominado vírus da leucemia felina (VLF), descoberto por Jarrett et al., em 1964, a partir de gatos que haviam desenvolvido linfossarcoma. Estudos experimentais realizados por esse grupo de pesquise dores demonstraram que o VLF se transmitia vertical e horizontalmente e que os animais infectados desenvolviam diversas formas de doenças mielo e linfoproliferativas ou degenerativas (Mackey et al., 1972).

Após a padronização de um teste de imunofluo- rescência para a detecção de antígenos do VLF no sangue periférico dos felinos infectados, tornou-se possível estabelecer o diagnóstico da infecção viral em populações felinas. Estudos epidemiológicos extensos, valendo-se desse método bem como de outros, como o teste imunoenzimático, revelaram ser a infecção relativamente freqüente, disseminando-se de uma forma contagiosa entre felinos que vivem em um mesmo ambiente (Barlough, 1983). Segundo Francis et al. (1977) e Lutz et al. (1983) a transmissão ocorre através da saliva.

A afinidade do VLF por células do tecido hematopoiético, independente da linhagem celular, resulta no desenvolvimento de doenças como linfossarcoma, anemia não-regenerativa, síndrome panleucopênica e atrofia do timo; no envolvimento da infecção viral em uma ampla variedade de distúrbios mieloproliferativos ou degenerativos; e ainda, em desordens da reprodução (Barlough, 1983; Hardy, 1987). Por ser um agente imunossupressivo, pode conduzir ao desenvolvimento de doenças secundárias, mormente as infecciosas, sendo considerado na atualidade como um dos agentes envolvidos na síndrome de imunodeficiência adquirida dos felinos domésticos (Olsen et al., 1987; Hagiwara et al., 1989).

Pela ampla magnitude das manifestações clínicas e a disseminação generalizada do vírus, principalmente em populações de gatos mantidos em confinamento ou em criatório, o teste de leucemia felina tornou-se praticamente obrigatório na clínica de felinos, não se restringindo a sua indicação apenas em animais com neoplasias linfóides. O desenvolvimento do teste imunoenzimático (ELISA test) tornou o diagnóstico acessível à maioria dos médicos veterinários e a sua utilização em nível de clínicas veterinárias.

Através da utilização do teste imunoenzimático para a detecção da antigenemia, demonstrou-se, em 1984, que nenhum dos 198 felinos não domiciliados da cidade de São Paulo apresentou reação positiva ao teste, ao passo que a infecção foi observada em cinco dos 128 felinos

\footnotetext{
${ }^{1}$ Departamento de Clínica Médica, Faculdade de Medicina Veterinária e Zootecnia, FMVZ, Universidade de São Paulo, USP, Av. Orlando Marques de Paiva 87, 05508-900 São Paulo, SP, Brasil. Email: mkhagiwa@spider.usp.br

2 Doutorando do Departamento de Clínica Médica, FMVZ, USP.
} 
domiciliados, atendidos no Hospital Veterinário da Faculdade de Medicina Veterinária e Zootecnia da Universidade de São Paulo, portadores de diversas condições mórbidas (Hagiwara et al., 1984).

Prosseguindo no estudo, procurou-se estudar a freqüência da infecção entre os animais doentes com a finalidade de avaliar a existência de possíveis associações entre a infecção e o desenvolvimento de diferentes quadros mórbidos.

\section{Material e Métodos}

No período de 1985 a 1991, foram obtidas 298 amostras de sangue periférico ou de soro sangüíneo, dos felinos doentes atendidos no Hospital Veterinário da Faculdade de Medicina Veterinária e Zootecnia da USP ou de animais sadios, contactantes daqueles portadores do VLF, que foram submetidos ao teste de leucemia felina. Distúrbios gastroentéricos, principalmente diarréia, problemas respiratórios decorrentes da infecção pelo vírus da rinotraqueíte infecciosa, calicivírus ou Chlamydiasp., processos febris de causas diversas, anemia, icterícia, processos neoplásicos de origem hematopoiética, dermatopatias, anorexia prolongada e perda de peso haviam sido os principais problemas observados que motivaram a realização de exames subsidiários para a elucidação diagnóstica, incluindo-se entre eles o teste para a leucemia felina.

As amostras de sangue foram colhidas por meio da venipunctura jugular ou radial. Na maioria dos casos, o teste imunoenzimático foi realizado com amostra de soro sangüíneo, porém, quando isto não foi possível, utilizouse sangue total com anticoagulante (EDTA sódico).

Para o diagnóstico da leucemia felina, foram utilizados kits comerciais baseados no teste imunoenzimático para a detecção de antígenos circulantes do VLF (Leukassay F., Pitman Moore Inc. ou Dya Sistems, Tech America). As provas foram realizadas conforme instruções dos respectivos fabricantes e consideradas positivas apenas quando a cor desenvolvida na reação final era igual ou mais intensa do que a obtida com o padrão positivo. As reações de intensidade moderada a fraca, consideradas de suspeição diagnóstica, não foram computadas no presente estudo, quando os testes foram repetidos trinta dias após, com nova amostra de sangue, e o resultado mostrou-se negativo.

\section{Resultados}

Do total dos 298 animais submetidos ao teste de leucemia felina, 37 felinos, correspondendo a $12,5 \%$ dos casos, se revelaram infectados pelo retrovírus felino responsável pelo complexo leucemia felina. A maioria dos animais infectados situava-se na faixa etária de 30 a 36 meses, sendo a idade média de $32,3 \pm 3,5$ meses. O felino mais jovem, nascido de uma gata portadora do vírus, que veio a óbito por apresentar atrofia do timo, tinha apenas um mês de idade e o mais velho, portador de carcinoma epidermóide, tinha doze anos de idade.

Aparentemente, os machos são mais suscetíveis à infecção, tendo respondido por $67,5 \%$ dos casos (25/37). Quanto à raça dos animais infectados, 23 felinos não tinham raça definida e os demais (14) eram da raça siamesa, não tendo sido observada a infecção em animais de outras raças. Deve-se salientar que todos os animais da raça siamesa pertenciam ao mesmo proprietário.

A distribuição dos casos positivos para o teste de leucemia felina, de acordo com o diagnóstico clínico efetuado, encontra-se na Figura. Nos animais positivos, hemobartonelose foi o diagnóstico clínico mais freqüente, respondendo por 10 dos 37 casos positivos, seguindo-se linfoma (7), icterícia e febre (3), peritonite infecciosa felina (2), anemia hipoplásica (2), uveíte (2), complexo eosinofílico dos felinos (2), trombocitopenia (2), periodontite (2), atrofia do timo (1), complexo respiratório (2) e carcinoma epidermoide (1). Um dos animais positivos era assintomático, contactante de outro animal portador da infecção.

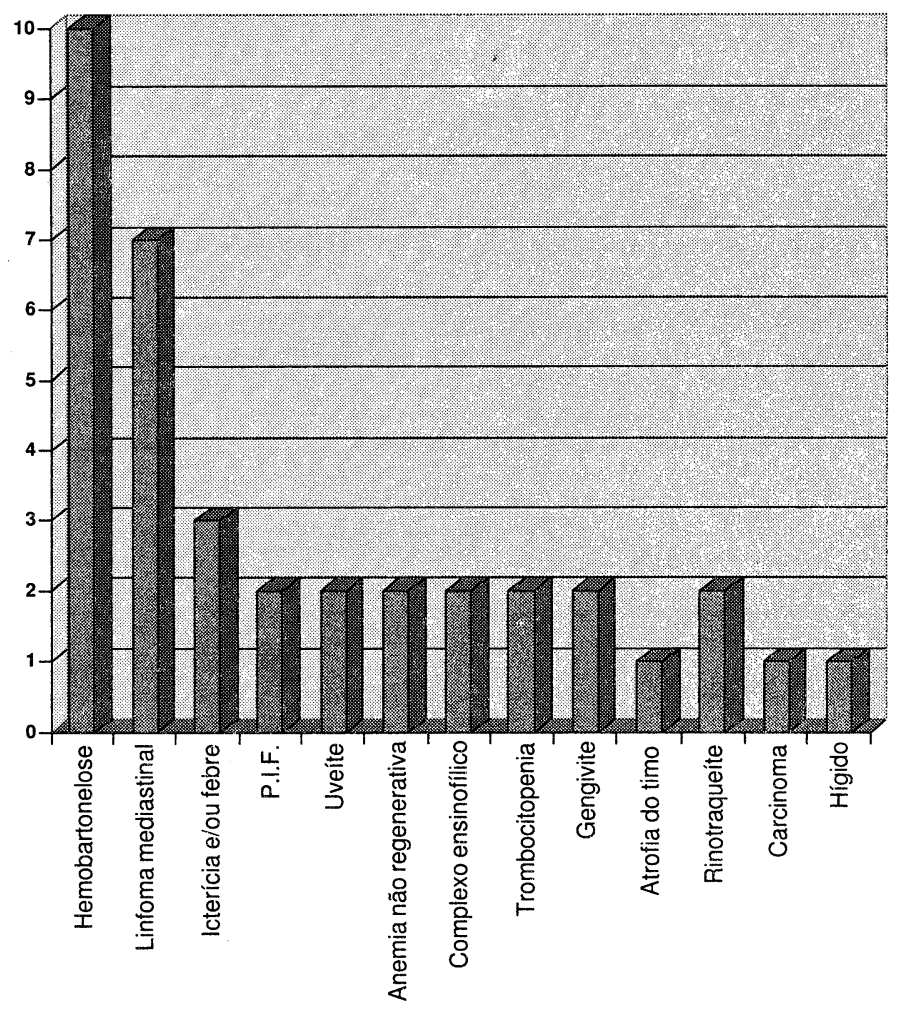

Figura - Distribuição dos casos de infecção pelo vírus da leucemia felina segundo o diagnóstico clínico.

P.I.F.: peritonite infecciosa felina 


\section{Discussão}

A infecção de felinos pelo VLF é relativamente comum em São Paulo, como se observa pela análise dos resultados obtidos, estando associada a um amplo espectro de doenças infecciosas e não-infecciosas, como já havia sido relatado por diversos autores (Rojko et al., 1979; Hardy, 1981, 1987; Olsen et al., 1987). Sabe-se que infecções oportunistas, como a hemobartonelose instalam-se em animais com alterações da defesa imunológica, como ocorre na infecção pelo retrovírus felino, cujo efeito devastador sobre o sistema imunológico é amplamente conhecido (Olsen et al., 1987). Justifica-se assim a alta proporção de felinos positivos ao teste de leucemia felina entre os animais que se apresentaram com anemia de origem infecciosa.

A peritonite infecciosa felina, outro processo de etiologia viral observado freqüentemente em associação com a infecção pelo VLF, foi menos freqüente entre os casos estudados, contrapondo-se aos dados citados na literatura (Barlough,1983).

Entre os animais que haviam apresentado neoplasias de origem linfóide, os resultados positivos para o teste de leucemia felina foram encontrados naqueles que apresentaram a forma mediastinal da doença, enquanto as formas multicêntricas encontradas no presente estudo não estavam, aparentemente, relacionadas à infecção pelo retrovírus felino. A maior frequeência de tumores mediatinais entre os felinos infectados pelo VLF é citada por Hardy (1987). A negatividade ao teste imunoenzimático não exclui a possibilidade de que os felinos fossem portadores de infecção latente localizada na medula óssea, sem viremia aparente, nos quais a infecção de linfócitos houvesse resultado previamente na sua transformação neoplásica. Nessas circunstâncias, o teste de leucemia felina, baseado na antigemia resultante da infecção produtiva, não é capaz de identificar os animais infectados.

Por outro lado, a sensibilidade do teste imunoenzimático é considerada maior que a do teste de imunofluorescência, podendo fornecer resultados falsopositivos (Jarrett et al., 1982), indicando a necessidade da repetição do teste naqueles animais em que a reação for fracamente positiva ou quando houver dúvidas quanto ao diagnóstico. A maioria dos animais, nos quais se estabeleceu o diagnóstico etiológico, apresentava quadros mórbidos graves, ocorrendo o óbito algum tempo depois. A positividade ao teste foi confiimada em repetidos exames.

No caso de dúvida, diversos pesquisadores indicam a utilização do teste de imunofluorescência que apresenta especificidade e concordância em cerca de $95 \%$ com o método de isolamento do vírus (Jarrett et al., 1982). A confirmação da infecção pelo VLF é necessária principalmente quando se indica a eutanásia dos animais infectados.

O teste imunoenzimático tem-se revelado bastante útil na triagem dos felinos infectados pelo VLF; na impossibilidade de se usar testes mais complexos como o teste de imunofluorescência ou cultura de tecidos para o isolamento do vírus, constituiu-se a única alternativa válida para o diagnóstico da infecção viral.

A ampla variedade de doenças observadas nos felinos em que se diagnosticou a viremia justifica plenamente a denominação de complexo leucemia felina dada ao conjunto de entidades mórbidas associadas à infecção ativa pelo VLF, tornando-se mandatória a indicação do teste de leucemia felina ao lado do teste imunoenzimático para o diagnóstico da infecção pelo vírus da imunodeficiência dos felinos naqueles animais que apresentam doenças crônicas, de origem infecciosa ou não (Hagiwara et al., 1989).

\section{Conclusões}

1. A infecção dos felinos pelo VLF é relativamente comum em São Paulo e está associada a uma ampla gama de moléstias infecciosas ou não-infecciosas.

2. Embora a infecção seja mais freqüentemente diagnosticada em felinos adultos jovens, pode ser observada em animais de qualquer idade.

3. É impossível indicar-se a necessidade do teste de leucemia felina com base exclusivamente no diagnóstico clínico, devendo o teste ser realizado nos felinos que se apresentarem com doenças crônicas de origem infecciosa ou não.

\section{Abstract \\ Clinical studies of feline leukemia virus infection among cats in São Paulo}

Serum samples from 298 sick cats were submitted to enzyme linked immunosorbent assay for detecting feline leukemia virus (Felv) antigen (Leukassay F., Pitman Moore), aiming to evaluate the frequence of Felv infection among domestic cats. Thirty seven Felv (12.5\%) positive cats were found. The reagents were observed among cats with clinical diagnosis of hemobartonellosis (10), mediastinal lymphoma (7), jaundice and fever (3), feline infectious peritonitis (2), hypoplastic anemia (2), uveitides (2), gastroenteritidis (2), trombocytopenia (1), periodontitides (2), atrophy of thymus (1), chronic respiratory disease (1), carcinoma (1), and asymptomatic (1). The great majority of cats were 30 to 36 months old, being the youngest one month old and the oldest one, twelve years. Felv infection was more frequent among male cats $(67.5 \%)$ and in short haired domestic cats.

Key words: cats; feline leukemia; virus

\section{Referências bibliográficas}

Barlough JE 1983. Feline leukemia virus. Information Bulletin, 
Cornell Feline Health Center, 5: 1-7.

Francis DP, Essex M, Hardy Jr WD 1977. Excretion on feline leukemia virus by naturally infected pet cats. Nature 269: 252-254.

Hagiwara MK, Dahmmer HVPF, Larsson CE, Prado MSS 1984. Prevalência da infecção pelo vírus da leucemia felina em felinos domésticos de São Paulo. Dados preliminares. Anais, VII Congresso Brasileiro de Clínicos Veterinários de Pequenos Animais, Rio de Janeiro.

Hagiwara MK, Dahmmer HVPF, Reche JR 1989. A síndrome de imunodeficiência adquirida dos felinos domésticos. Cães e gatos 26: 14-18.

Hardy Jr WD 1981. The feline leukemia virus. J Am Animal Hosp Assoc 17: 951-980.

Hardy Jr WD 1987. Oncogenic viruses of cats: the feline leukemia and sarcoma viruses, p. 246-248. In J Holzworth, Diseases of the cat: Medicine and surgery. WB Saunders Co, Philadelphia.

Jarret WFH, Crawford EM, Martin WB, Davie F 1964. A virus-like particle associated with leukemia (lymphossarcoma). Nature 202: 567-568.

Jarret O, Golder MC, Weiser K 1982. Ein Vergleich von drei Methoden der Felinen Leukemia Virus Diagnose. Kleintierpraxis 27: 241-246.

Lutz H, Pedersen NC, Theilen G 1983. Course of feline leukemia virus infection and its detection by enzyme-linked immunossorbent assay and monocital antibodies. Amer $J$ Vet Res 44: 1054-1059.

Mackey LJ, Jarret WFH, Jarret O, Laird HM 1972. An experimental study of virus leukemia in cats. $J$ Nat Cancer Inst 48: 1663-1670.

Olsen RG, Lewis MG, Lafrado LJ, Mathes LE, Haffer K, Sharpee R 1987. Feline leukemia virus: current status of the feline leukemia induced immunodepression and prevetion. Cancer Med Rev 6: 243-260.

Rojko JL, Hoover EA, Mathes LE, Olsen RG, Schaller JP 1979. Pathogenesis of experimental feline leukemia virus infection. J Nat Cancer Inst 63: 759-768. 